ISSN 2236-0859

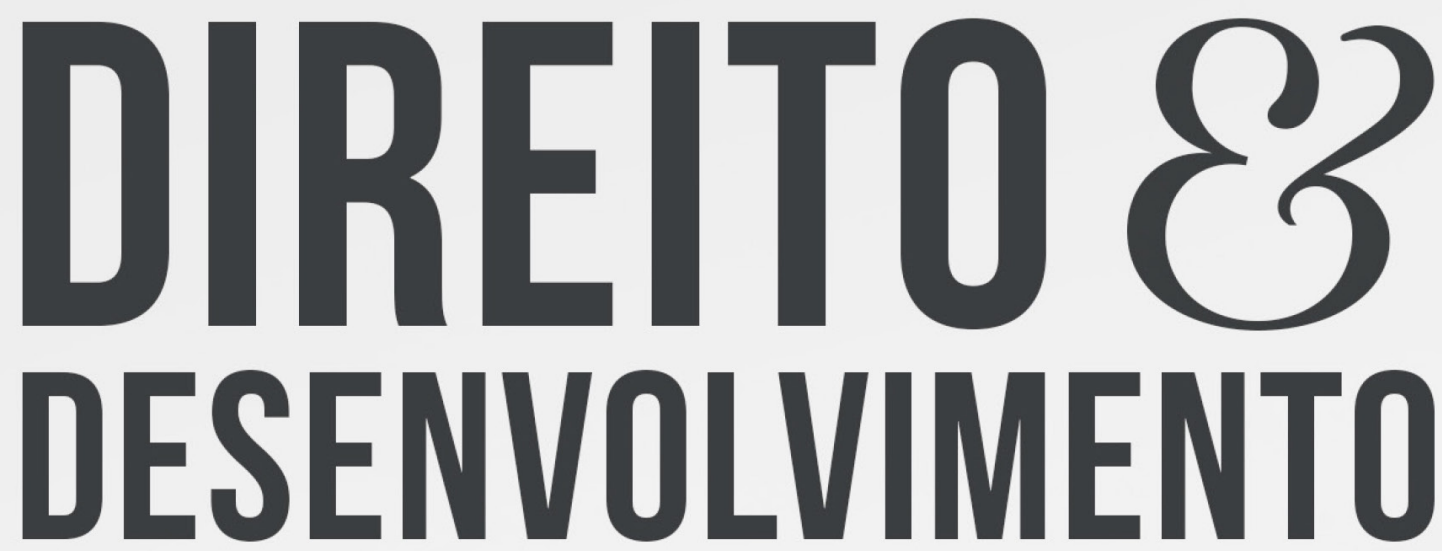

REVISTA DO PROGRAMA DE PÓS-GRADUAÇ̃̃O EM DIREITO MESTRADO EM DIREITO E DESENVOLVIMENTO SUSTENTÁVEL

OS POVOS INDÍGENAS BRASILEIROS NA DITADURA MILITAR: TENSÕES SOBRE DESENVOLVIMENTO E VIOLACSÃO DE DIREITOS HUMANOS

RAFAEL LAMERA GIESTA CABRAL VITÓRIA LARISSA DANTAS DE MORAIS 


\title{
OS POVOS INDÍGENAS BRASILEIROS NA DITADURA MILITAR: TENSÕES SOBRE DESENVOLVIMENTO E VIOLAÇÃO DE DIREITOS HUMANOS
}

\section{BRAZILIAN INDIGENOUS PEOPLE IN MILITARY DICTATORSHIP: TENSIONS ABOUT DEVELOPMENT AND HUMAN RIGHTS VIOLATION}

Recebido: 13/04/2020

Aprovado: 26/06/2020
Rafael Lamera Giesta Cabral ${ }^{1}$ Vitória Larissa Dantas de Morais ${ }^{2}$

\section{RESUMO:}

Este artigo buscou analisar a violação de direitos fundamentais dos indígenas brasileiros durante a ditadura militar no Brasil, dentro do marco desenvolvimentista que caracterizou o período de 1964-1985. Para atingir o objetivo, essa pesquisa utilizou como fonte documental o Relatório da Comissão Nacional da Verdade, que possui seção específica sobre os povos indígenas. Ao lado das fontes documentais, realizou-se pesquisa bibliográfica, a fim de problematizar as principais violações desse período, a partir do campo dos estudos da história do tempo presente. Como resultado, observa-se a violação aos direitos indígenas foi camuflada sobre o argumento de que os indígenas eram um empecilho para o desenvolvimento do país, com consequências no presente.

Palavras-chave: Índios. Ditadura. Violação. Direitos. CNV.

\begin{abstract}
:
This article sought to analyse the violation of fundamental rights of brazilian indigenous people during the military dictatorship in Brazil, during the desenvolvimentist mark which characterized the period of 1964-1985. To achieve the objective, this research used as a documentary source the Report made by the Nacional Truth Report, which has a specific section about indigenous people. Besides the documentary sources, a bibliographic research was realized, in order to problematize the main violations of this period, based on the studies of the present time's history. As result, it was possible to observe that the violation of indigenous rights was camouflaged by the argument that indians were an obstacle to the development of the country, which brought consequences for the present.
\end{abstract}

Keywords: Indians. Dictatorship. Violation. Rights. NTC.

Classificação Journal of Economic Literature (JEL): Kı, K38 (Human Rights Law; Gender Law).

1 Doutor em Direito, Estado e Constituição pela Universidade de Brasília - UnB (2016). Mestre em Ciência Política pela Universidade Federal de São Carlos - UFSCar (2010) e Bacharel em Direito pela Universidade Estadual de Mato Grosso do Sul - UEMS (2007). Atualmente, é professor adjunto no curso de Direito e Coordenador do Programa de Pós-Graduação Stricto Sensu em Direito (Mestrado Acadêmico) e docente no Programa de Pós-Graduação em Administração Pública (PROFIAP Mestrado Profissional) da Universidade Federal Rural do Semi-Ârido (UFERSA).E-mail: rafaelcabral@ufersa.edu.br

2 Mestranda em Direito Constitucional pela Universidade Federal Rural do Seminárido (UFERSA). É estagiária de pós-graduação no programa de Residência da Defensoria Pública do Estado do Rio Grande do Norte, atuando na área cível. Bacharela em Direito pela Universidade Federal Rural do Semiárido (UFERSA).. E-mail: vitorialarissa@hotmail.com. 


\section{INTRODUÇÃO}

Nos últimos anos, as violações aos direitos indígenas têm se acentuado. Com práticas cada vez mais articuladas, os homicídios de lideranças indígenas têm-se naturalizado em vários estados do país.

Os homicídios perpetrados contra os indígenas da etnia Guajajara, no estado do Maranhão, podem ser um bom exemplo desse cenário, sobretudo pelas disputas territoriais entre grileiros, fazendeiros e indígenas, que enfrentam uma onda de invasões e roubos de madeira em seu território.

Essas demandas do tempo presente têm mobilizado pesquisadores das mais diversas áreas do conhecimento e os colocados em estado de atenção: as mudanças na política indigenista da Fundação Nacional do Índio - FUNAI, instauradas a partir do Governo Federal (2019-?), o incentivo às narrativas de que os indígenas são improdutivos e que, por essa razão, suas terras devem ser exploradas (minério, hidrelétricas e pastagens para animais), somadas as disputas territoriais dos indígenas, impactados com a Súmula 650, do Supremo Tribunal Federal - STF, completam o cenário de preocupações.

A Súmula 650, do STF, consolidou o entendimento na corte de um marco temporal para o reconhecimento de terras tradicionalmente ocupadas pelos índios, em caso de disputas territoriais, que passaria a levar em consideração a data de 05 de outubro de 1988, quando a Constituição Federal de 1988 foi promulgada.

As reações dos índios e das entidades da sociedade civil de proteção aos direitos indígenas foram imediatas e levantaram um problema relevante, mas ignorado pelo STF: a ditadura militar também incluiu os povos indígenas dentro do marco da Doutrina da Segurança Nacional - DSN, considerando-os inimigos internos, com tendências a impedir o desenvolvimento do país. A consequência imediata desse movimento, não exclusivo do tempo da ditadura militar, mas aprimorado a partir dessa experiência autoritária, foi o remanejamento involuntário dos indígenas de suas terras tradicionais.

O objetivo deste artigo foi investigar, a partir da narrativa produzida pelo Relatório da Comissão Nacional da Verdade - CNV, as graves violações aos direitos indígenas promovidos ao tempo da ditadura militar pelos agentes de Estado, caracterizada contextualmente dentro do marco do desenvolvimentismo, imposto pela política econômica do governo militar.

Para tratar do tema com mais profundidade, a CNV elaborou um Relatório, entre 2012 e 2014, que investigou e descreveu o cenário do país durante o período em comento. Como parte do projeto do Grupo de Trabalho da Comissão Nacional da Verdade sobre Graves Violações de Direitos Humanos no Campo ou Contra Indígenas, foi escrito um capítulo inteiramente destinado à crise vivenciada pelos povos indígenas brasileiros.

O capítulo do Relatório que falava sobre a temática indígena conta com pouco mais de 50 páginas e retrata violações aos Direitos Humanos desses povos durante a ditadura militar. São vários exemplos, desde remoções forçadas a contaminações propositais, promovidas por agentes de Estado, via órgãos que deveriam oferecer proteção àqueles povos, como o Serviço de Proteção ao Î́ndio - SPI e a Fundação Nacional do Índio - FUNAI.

Apesar de o próprio Relatório assumir suas limitações em razão da grande possibilidade de se desconhecer inúmeros casos, seu conteúdo contémgrande avanço para a temática indígena.

A iniciativa faz parte de uma série de projetos de Justiça de Transição que buscam trazer visibilidade àqueles que foram vítimas das arbitrariedades cometidas em um período repleto de ilegalidades. A Justiça de Transição, que pode ser definida como um conjunto de ações e estudos que visam superar momentos de conflito e de violação de direitos humanos contra 
determinado grupo social, tem como base a promoção dos direitos à Memória e à Verdade (VAN ZYL, 2009; SELIGMANN-SILVA, 2009; SANTOS, 2009; MARQUES, 2018).

Tais direitos, por sua vez, têm como objetivo trazer, com transparência, o que de fato ocorreu em determinado período, fazendo com que a sociedade conheça os diversos crimes cometidos, bem como as vítimas, os culpados e os danos causados. A Comissão Nacional da Verdade buscou, portanto, trazer à tona a verdade acerca dos acontecimentos do período militar, desmistificando e desmentindo fatos ocultados ou omitidos pelo governo da época.

Teoricamente, essa investigação está amparada no campo da História do Direito, com aderência na história do tempo presente, que se tem voltado para analisar as rupturas e ou permanências do passado no presente (DELGADO; FERREIRA, 2013).

Para que o objetivo fosse alcançado, fontes documental e bibliográfica foram mobilizadas a partir do Relatório da CNV, que possui um capítulo específico para tratar das violações aos direitos dos povos indígenas, e de pesquisas produzidas por historiadores, antropólogos e juristas (publicadas em livros, artigos especializados e em dissertações e teses).

Essa pesquisa foi organizada em três partes: na primeira, esboçou-se a legislação indigenista na ditadura militar com o contexto desenvolvimentista da ditadura militar; nas duas últimas, respectivamente, avançou-se sobre a abordagem do Relatório da CNV, com destaque às violações aos direitos humanos.

\section{A LEGISLAÇÃO INDIGENISTA E O DESENVOLVIMENTISMO NACIONAL NA DITADURA MILITAR}

A memória ativa sobre o período ditatorial vivenciado no Brasil após o Golpe de 1964, remonta a uma disputa de narrativas que caracterizam o tempo presente: no mesmo momento em que é possível reconhecer que houve violações de direitos em grande parte do país, com torturas contra os que defendiam a democracia ou a causa revolucionária, de censura aos intelectuais nas universidades, de atividades jornalísticas e de artes, como os teatros, também é possível registrar as teses negacionistas ou da "pós-verdade", que ancoradas no anti-intelectualismo, defendem o período da ditadura militar (em tom saudosista) como uma medida necessária para livrar o país do comunismo.

Sem negar os pressupostos de cada uma dessas abordagens, que não só podem como devem ser problematizadas, há determinados postulados científicos que, se forem negligenciados, promovem revisionismos que só dialogam com o senso comum, que sempre está livre ao sabor das circunstâncias políticas de polarização do presente.

Esse cuidado a priori aplica-se ao tipo de teoria que se busca desvelar as violações dos direitos dos povos indígenas no presente. $\mathrm{O}$ retorno ao passado permite reinterpretar esses dilemas. A seguir, passa-se a explorar um histórico da legislação indigenista, com especial atenção ao período da ditadura militar.

A normatização e proteção dos assuntos atinentes aos povos indígenas se deu por meio de um processo lento e gradual, intermediado pelo Serviço de Proteção ao Índio - SPI. No Código Civil de 1916, os índios foram incluídos no rol de relativamente incapazes. ${ }^{3}$ Além disso, até 1926, as questões indígenas ainda estavam muito atreladas à igreja e à ação missionária (PAULETTI, 2000).

A ruptura ocorreu com o Decreto no 5.484, de 24 de junho de 1926 , que retirou o caráter religioso e missionário do trabalho desenvolvido junto às populações indígenas, apesar de não

3 Para a evolução no tratamento penal, ver Silva (2017). 
ter estabelecido nenhuma proibição no que se refere à continuidade das atividades missionárias (SOUZA FILHO, 2012).

Em 1934, os índios brasileiros tiveram seus direitos tutelados pela Constituição, a qual reconheceu, em seu art. 129, o respeito à posse de terras indígenas, vedando, ainda, a possibilidade de alienação dessas terras. Por último, atribuiu à União a competência para elaborar normas acerca da incorporação dos silvícolas - termo utilizado à época - à comunidade nacional.

Até então, o ordenamento jurídico brasileiro tratava o índio como incapaz, além de ser constantemente defendida a necessidade de integração à sociedade. Por isso, lhe era conferido um regime diferenciado de proteção. Coma Lei no 4.121 de 27 de agosto de 1962, ficou estabelecido que os povos indígenas ficariam sujeitos ao regime da tutela, que cessaria após a adaptação à sociedade não-índia. Nesse período, a figura da incapacidade passou a ser atribuída somente àqueles que ainda não estavam incorporados ao que se considerava sociedade civilizada, termo e conceito hoje já ultrapassados (BARRETO, 2014).

O Serviço de Proteção ao Índio funcionou até 1967, já na ditadura militar, quando foi substituído pela Fundação Nacional do Índio - FUNAI. A história do SPI, além de controversa, reflete uma política indigenista questionável sob todos os ângulos possíveis. ${ }^{4} \mathrm{O}$ instituto surgiu em decorrência tanto dos problemas e crises internas em relação aos povos indígenas, quanto da pressão internacional contra o Brasil, acusado de massacres aos índios já em 1908, no XVI Congresso de Americanistas, em Viena (Áustria), segundo relata Abreu (2001), e foi extinto em decorrência de uma CPI, fartamente documentada pelo Relatório Jarbas Figueiredo.5

Em apenas parte de um fragmento do Relatório Figueiredo (BRASIL, 1968, p. 4.912), registrou-se que "a Comissão constatou, de início, a geral corrupção e anarquia total imperantes no SPI em toda a sua área, também através dos tempos. A gama inteira de crimes ali se praticavam, ferindo as normas do Estatuto, do Código Penal e do Código Civil”. Mais à frente, o relatório informava que:

Os delitos cometidos podem ser apresentados grupados por espécie, conforme o esquema abaixo:

1. CRIMES CONTRA A PESSOA E A PROPRIEDADE DO ÍNDIO

1.1 Assassinatos de índios (individuais e coletivos: tribos)

1.2 Prostituição de índias

1.3 Sevícias

1.4 Trabalho escravo

1.5 Usurpação do trabalho do índio

1.6 Apropriação e desvio de recursos oriundos do patrimônio indígena

1.7 Dilapidação do patrimônio indígena

a) Venda de gado

b) Arrendamento de terras

c) Venda de madeiras

d) Exploração de minérios

e) Venda de castanha e outros produtos de atividade extrativistas e de colheita

f) Venda de produtos de artesanato indígena

g) Doação criminosa de terras

h) Venda de veículos

2. ALCANCE DE IMPORTÂNCIAS INCALCULÁVEIS

3. ADULTERAÇÃO DE DOCUMENTOS OFICIAIS

4. FRAUDE EM PROCESSO DE COMPROVAÇÃO DE CONTAS

5. DESVIO DE VERBAS ORÇAMENTÁRIAS

6. APLICAÇÃO IRREGULAR DE DINHEIROS PÚBLICOS

4 Para maiores detalhes, ver Freire, 2011.

$5 \mathrm{O}$ relatório foi considerado perdido por aproximadamente 40 anos. Redescoberto, o Relatório Figueiredo pode ser acessado no portal eletrônico do Museu do Índio, disponível em: < http://www.docvirt.com/docreader.net/DocReader.aspx?bib=museudoindio > 
7. OMISSÕES DOLOSAS

8. ADMISSÕES FRAUDULENTAS DE FUNCIONÁRIOS

9. INCÚRIA ADMINISTRATIVA.

Tamanhos são os crimes. O Serviço de Proteção aos Índios degenerou a ponto de persegui-los até ao extermínio. Relembrem-se aqui os vários massacres, muitos dos quais denunciados como escândalo, sem, todavia, merecer maior interesse das autoridades. (BRASIL, 1968, p. 4915-6).

A FUNAI surgiu em meio a um complexo legado deixado pelo SPI, mas que na essência não se diferenciou muito de outros problemas comuns à gestão indígena. Um dos elementos fundamentais para esse cenário foi a vinculação do novo instituto ao Ministério do Interior.

Os objetivos da FUNAI, que atendia aos reclamos de uma política fortemente marcada pela perspectiva assimilacionista, e do Ministério do Interior se compenetram com os planos de defesa nacional, construção de estradas, hidrelétricas e ocupação territorial por meio de fazendas.

A narrativa a ser produzida, em média e longa escala, era identificar no índio ou comunidade indígena resistente a pecha de entrave ao desenvolvimento nacional. O movimento desenvolvimentista da ditadura militar foi muito mais agressivo que o já iniciado por Getúlio Vargas na década de 1940 com as "Marchas para o Oeste". Com aquela política de colonização, o governo de Getúlio Vargas, em apoio aos governos estaduais que já haviam promovido a ocupação de terras indígenas, como as do Estado do Paraná, ${ }^{6}$ implementou uma ação federal de exploração e ocupação do Centro-Oeste por colonos, que, segundo o CNV (BRASIL, 2014a, p. 206), "conta[tava] populações indígenas isoladas e favore[cia] a invasão e titulação de terras indígenas a terceiros".

Com o endurecimento da política indigenista, a partir do Ato Institucional n. 5 - AI-5, criam-se modificações que - a médio e longo prazo - favorecem o desmantelamento do sistema protetivo. Organizam-se prisões para os indígenas (um dos mais famosos foi o Reformatório Krenak e a Fazenda Guarani, em Minas Gerais), remoção forçada de índios para aldeamentos ocupados por inimigos tradicionais entre as etnias, e passam a compreender os índios como virtuais inimigos internos, em nome da segurança nacional. Fomenta-se a organização de uma guarda rural indígena (GRIN), em 1969,

[...] que recruta índios ao longo, sobretudo, do Araguaia e do Tocantins, além de Minas Gerais, para atuarem como força de polícia nas áreas indígenas. A princípio festejada, a GRIN foi acusada em um inquérito proveniente da Chefia da Divisão de Segurança e Informação do Ministério do Interior de arbitrariedades, espancamentos e abusos de toda sorte (BRASIL, 2014a, p. 212).

Além de sem terras e incitados em conflitos fundiários, a CNV constatou uma profunda omissão na política de saúde a partir de 1969, ao lado de uma forte política de assimilação cultural preconizada pelo plano de desenvolvimentismo do Estado que se caracterizou como um programa de etnocídio. Ao se descaracterizar os índios como sujeitos de direitos, promoveu-se uma desagregação social, como mortandades e massacres, com profunda perseguição política ao movimento indígena.

O custo social, político, econômico e cultural para manter essa narrativa foi destrutivo. No entanto, corresponde a um controle sobre uma dimensão da memória social que se projeta para o futuro. Ser indígena em Mato Grosso do Sul ou em outros estados com conflitos

6 No relatório, registra-se que "entre 1930 e 196o, o governo do Estado do Paraná titula terras indígenas para empresas de colonização e particulares no oeste do estado. O governo Moysés Lupion, em particular, notabiliza-se por práticas de espoliação de terras indígenas. Os interesses econômicos de proprietários se faziam representar nas instâncias de poder local para pressionar o avanço da fronteira agrícola sobre áreas indígenas" (BRASIL, 2014a, p. 206). 
territoriais é desafiar um legado de preconceitos que foram construídos nos espaços público, privado, institucional, político, religioso, cultural e social (CABRAL, 2020).

A ditadura militar exerceu grande influência nesse movimento. Os relatos apontados no relatório da CNV são um bom indicativo para compreendermos alguns pontos de partida. Embora tenha atuação abrangente, o relatório deixou pistas para futuras investigações, com informações e dados suficientes para a construção de um belo programa de pesquisa sobre os indígenas na ditadura militar

Durante o período militar, vale ressaltar os dispositivos inseridos na Constituição de 1967 e na Emenda Constitucional no 1/69. Uma das grandes inovações foi a inclusão de um dispositivo que atribuía as terras indígenas ao patrimônio da União. Isso significa dizer que estaria afastado o processo de esbulho que vinha sendo praticado, além de ter centralizado definitivamente a questão indígena na esfera federal (ARAÚJO, 2006).

A partir de então, foi reconhecido também o direito do usufruto exclusivo dos recursos naturais presentes nas terras pelos próprios indígenas. Isso significa dizer que esses povos poderiam se utilizar de instrumentos jurídicos para proteger e lutar contra o desrespeito dessa garantia seja por fazendeiros, mineradoras e até órgãos governamentais. Essa foi uma grande novidade legislativa (ARAÚJO, 2006).

No que diz respeito à Constituição de 1969 , nos parágrafos $1^{\circ}$ e $2^{\circ}$ do seu artigo 198 , passaram a prever a nulidade e a extinção dos atos que tratassem da posse das terras indígenas, excluindo qualquer direito à indenização. Essa ação tornava inviável a alegação de que novos posseiros estariam protegidos sob o manto do direito adquirido (ARAÚJO, 2006).

Já o Estatuto do Índio, que data de 19 de dezembro de 1973, refletiu o pensamento dominante à época do regime militar ao tratar da necessidade de integração. Segundo Barreto (2014), durante esse período, adotava-se a perspectiva do evolucionismo unilinear-desenvolvida principalmente durante a primeira metade do século XIX -, que considerava o índio como um ser primitivo em processo de evolução. A teoria que se contrapõe é o evolucionismo multilinear, que acredita que a cultura só tem sentido se compreendida em suas mais diversas formas de manifestação (BARRETO, 2014).

Segundo Codato (2005), o período militar se desdobrou em uma espécie de processo pendular no qual se intercalavam períodos de maior e menor violência política. É possível visualizar tais momentos, por exemplo, quando se conferia certa proteção legal, enquanto, em outras situações, havia intensa violência.

Vale lembrar que, após o golpe de 1964, teve início uma nova dinâmica econômica no país. A fim de fomentar o desenvolvimento nacional, houve uma intensificação no planejamento de grandes construções e projetos exploratórios, que se espalharam pelo país. As ações, no entanto, desconsideraram importantes fatores sociais para a concretização das obras, como o contato e o deslocamento indígena nas áreas a serem modificadas.

Como abordado anteriormente, os povos indígenas passaram a ser vistos como obstáculos ao desenvolvimento nacional e essa opinião foi amplamente difundida, inclusive em espaços públicos:

Com o parco auxilio de quatro milhões de cruzeiros da SPVEA, a expedição na qual tomou parte veio revelar ao mundo cenas da vida de uma população selvagem que continua no mesmo estágio de antes do descobrimento do País. É incrível que, num país em desenvolvimento como o Brasil, onde todas as eras da civilização se recapitulam no presente, ainda existam populações nesse estágio de selvageria (TRINIDAD, 2018, p. 263, APUD Câmara dos Deputados, 23 de março 1962, p. 194-195).

Lacerda (2008) explica que, para os militares brasileiros, a promoção de desenvolvimento implicava a necessidade de construir, explorar e abrir estradas para escoar riquezas. Além 
disso, a exploração e a integração dessas modalidades nas faixas de fronteira, em especial na Amazônia, significava promover a segurança do país. Sendo assim, o Plano de Integração Nacional (PIN), passou a contar com dois objetivos básicos: a segurança de áreas consideradas fragilizadas e a promoção de desenvolvimento em áreas consideradas "vazios demográficos". Nesse momento, surge verdadeira aliança entre Forças Armadas e setores econômicos interessados no aproveitamento das riquezas naturais existentes nas terras indígenas.

A partir da década de 70, quando houve a descoberta de reservas minerais na região amazônica pelo projeto RADAM (análise geológica do solo), as terras indígenas passaram a ser alvo constante. A pressão das empresas interessadas pela regularização das atividades levou à edição do Decreto no 88.985 , de 10 de novembro de 1983, que permitia a exploração mineral nas terras indígenas. $\mathrm{O}$ resultado não poderia ser outro: "mais de 17,6 milhões de hectares estavam sendo requeridos ou concedidos para mineração em 77 terras indígenas, sob controle de 69 empresas ou grupos econômicos (LACERDA, 2008, p. 25, APUD RICARDO; ROLLA. 2005, p.5).

Nota-se, portanto, que o arcabouço jurídico-normativo não conseguiu conter o que estava acontecendo, tampouco foi firme o suficiente para conter as inovações legislativas nocivas aos interesses indígenas. Para que se compreenda mais à fundo o teor das afirmações anteriores, é preciso que se conheça o que de fato ocorreu naquele período.

\section{O BRASIL INDÍGENA NA DITADURA MILITAR}

"Karí-tán-aitinnvaine Kre, Kêtt Kue n" ou, em português, "vocês civilizados mataram todos, tudo acabado" foi uma das formas pela qual o cacique Tariri, da tribo Tapayuna, expressou-se ao encontrar os ossos da sua noiva na mata, recém revirados por porcos selvagens. O relato foi presenciado pelo sertanista Antônio de Souza Campinas, enviado para aquela aldeia em 1971 em busca de sobreviventes (BRASIL, 2014a).

Os Tapayuna viviam no oeste de Mato Grosso e foram objeto de uma expedição organizada pela Fundação Nacional do Índio - FUNAI, em 1969. Estima-se que a população dos Tapayuna era de aproximadamente 1.220 pessoas. A tribo, no entanto, foi dizimada de várias formas (BRASIL, 2014a).

Envenenamento, armas de fogo, remoções forçadas e gripe. E o pior, tudo isso com aval do Estado. As expedições eram organizadas sem o menor zelo, não havia vacinas ou profissionais de saúde. A ausência de zelo, no entanto, não era suficiente para evitar que as expedições ocorressem. Especula-se, inclusive, que esse tipo de ação era proposital (BRASIL, 2014a).

Os Tapayuna não foram os únicos a serem alvos de ações desordenadas no período militar. Foram muitos os massacres ocorridos no Brasil entre 1964 até a redemocratização. Especula-se, vale acrescentar, que as violações de direitos não eram simplesmente ocasionais. Por vezes, foram cuidadosamente calculadas, pois faziam parte das políticas de ação do Estado em relação aos povos indígenas e as de expansão nacional (BRASIL, 2014a).

Quando grupos de oficiais militares apoiados por setores da sociedade civil derrubaram o presidente João Goulart por meio de um Golpe de Estado, o governo não sabia ao certo quantos índios havia no país. Estimava-se entre 70 e 110 mil. Mas tem-se conhecimento de que esse número era muito maior (VALENTE, 2017; MAGALHÃES, 2015).

O relatório acerca das violações de direitos humanos dos povos indígenas da Comissão Nacional da Verdade (2014a) estima que cerca de 8.350 indígenas foram mortos em decorrência da ação ou da omissão de agentes governamentais. O relatório deixa claro que essa estimativa 
leva em conta apenas casos documentados que davam margem a alguma estimativa. No entanto, enfatiza que o número de mortos e afetados deve ser muito maior, já que não se conhece com completude o que de fato ocorreu naquele período, tendo em vista que apenas uma pequena parcela dos afetados foi analisada.

O período de governos militares a ser analisado teve início em 1964 e terminou em 1985, quando teve fim o mandato do ex-Presidente João Batista Figueiredo. Apesar de ter sido encerrado ainda na década de 80 , as influências e consequências do período militar podem ser aferidas até os dias de hoje (ARAÚJO, 2006).

Para compreender as influências desse período para os povos indígenas é preciso falar sobre o Serviço de Proteção aos Índios e Localização dos Trabalhadores Nacionais - SPILTN, criado em junho de 1910 pelo Decreto no 8.072 e que, a partir de 1918, tornou-se apenas Serviço de Proteção aos Índios - SPI (ABREU, 2001). Esse órgão, vinculado ao Ministério da Agricultura, tinha influências positivistas e viva sob uma constante contradição desde a sua criação (FUNAI, 2013).

Enquanto era definido como órgão responsável pela proteção, preocupado em distanciar a igreja católica da catequese indígena para promover a diretriz republicana do Estado laico, tinha como principal objetivo o de civilizar os indígenas de forma a transformá-los em trabalhadores nacionais e/ou produtores rurais (FUNAI, 2013).

Uma das comunidades atingidas pelas ações do SPI foi a dos Xetá. Sobreviventes relatam a desagregação sofrida em razão da dispersão compulsória para as áreas indígenas Guarani e Kaingang. Há, inclusive, denúncias contra funcionários do SPI acerca de sequestros de crianças Xetá que foram distribuídas para famílias nãoindígenas e que foram forçadas a assumir novos hábitos e costumes (BRASIL, 2014a).

Em decorrência da dispersão, os Xetá foram considerados extintos durante o período ditatorial. Foi só na década de 90 que os sobreviventes daquela etnia se reencontraram e se uniram para ter reconhecidas sua cultura e a terra tradicional da qual foram removidos (BRASIL, 2014a).

Ainda na década de 40, Getúlio Vargas deu início à chamada "Marcha para o Oeste", uma política de exploração e ocupação do Centro-oeste, que fomentou o contato, inclusive, com tribos indígenas isoladas. Essa ação favoreceu e muito a invasão e a titulação de terras indígenas a terceiros. Tal política, destaque-se, já vinha sendo adotada por governos estaduais como uma espécie de colonização dirigida. (BRASIL, 2014a).

Nota-se, portanto, que as violações às prerrogativas indígenas já vinham ocorrendo desde antes do Golpe Militar de 1964, apesar de os direitos territoriais indígenas estarem previstos na Constituição de 1934, mais especificamente em seu artigo 129. Ocorre que tais investidas, como será visto, foram intensificadas no período ditatorial.

Em 1967, houve uma Comissão Parlamentar de Inquérito - CPI na Assembleia Legislativa do Rio Grande do Sul e um Relatório realizado pela comissão de investigação do Ministério do Interior denominado "Relatório Figueiredo". Essas iniciativas motivaram a extinção do SPI e a posterior criação da FUNAI. Mas a realidade indígena não tomou rumos melhores após a criação da FUNAI em 1967 (BRASIL, 2014a).

Em 13 de dezembro de 1968, teve início o episódio conhecido como "missa negra". Costa e Silva deu início à $43^{\mathrm{a}}$ reunião do Conselho de Segurança Nacional com o intuito de frear uma possível revolução. Nessa oportunidade, o texto do Ato Institucional no 5 foi apresentado e alguns presentes, como Pedro Aleixo, foram contra a outorga do AI. De nada adiantou (BARBOSA, 2012).

$\mathrm{O}$ AI-5 foi aprovado e marcou o início de uma política indigenista ainda mais agressiva, inclusive com a criação de presídios específicos para indígenas. Dois anos depois foi editado 
o Plano de Integração Nacional - PIN, responsável por promover uma possível ocupação da Amazônia, que era vista como verdadeiro vazio populacional, ignorando totalmente a existência de índios na região (BRASIL, 2014a).

Essa política tinha como forma de atuação a abertura de estradas, dentre elas a Transamazônica e a BR 163, de Cuiabá a Santarém. Somente a Transamazônica (BR-230) atravessou os estados da Paraíba, Piauí, Maranhão, Pará e Amazonas, vindo a atingir mais de 20 povos indígenas, como os Parintintin (PA), Pirahã (AM), Tenharim (AM), Munduruku (PA), Arara (PA), Assurini (PA), Juruna (PA), Kararahô (PA) e Apinajé (TO), sendo que vários deles ainda viviam isolados (LACERDA, 2008).

Essa previsão de abertura de estradas logo foi incorporada pela Lei no 6.o01/79, conhecida como o Estatuto do Índio, como sendo uma hipótese de intervenção da União para a realização de obras públicas de interesse do desenvolvimento nacional.

Na época, o Ministro do Interior, o político e militar José Costa Cavalcanti, confirmou saber o impacto das estradas nas comunidades quando declarou que a Transamazônica cortaria cerca de 29 etnias indígenas, sendo 11 grupos isolados. A FUNAI, por sua vez, firmou parceria com a Superintendência de Desenvolvimento da Amazônia (SUDAM) para a pacificação de 30 grupos indígenas arredios, tendo se tornado a executora dessa política de contato, atração e remoção de índios em benefício da construção das estradas (BRASIL, 2014a).

Práticas comuns que podem ser citadas foram contatos e remoções forçadas, presídios construídos para indígenas arredios, localidades nas quais foram realizadas torturas, dentre outros diversos tratamentos arbitrários.

A política indigenista também tinha como objetivo acelerar o processo denominado de desindianização. Havia um constante incômodo com a proteção dada às terras indígenas, sendo assim, a solução encontrada foi a adoção de políticas que visassem abolir de maneira concreta os detentores desses direitos (BRASIL, 2014a).

O programa de assimilação cultural pode ser visualizado como verdadeiro programa de etnocídio. Os idealizadores desse movimento positivista, presentes na origem do SPI, acreditavam na evolução desses povos, inclusive no que se refere às crenças religiosas. Dessa forma, os índios eram vistos como verdadeiros empecilhos ao desenvolvimento do país.

O cenário, como é de se imaginar, era de constante desespero. As expedições traziam epidemias, deixando muitos mortos. A índia Ngejwotxi, da aldeira Kawêrêtxikô no Xingu, ao relatar o que aconteceu com os Arinos, contou um episódio que demonstra as consequências das epidemias ocasionadas pelas expedições e pelas remoções forçadas:

\footnotetext{
O bebê chupava o peito da mãe morta, chorando, cheia de abelha no rosto, nos olhos, entrando no nariz. E esses meninos e meninas de cinco anos acima, eles seguiram, mas não chegaram na aldeia, não alcançaram o pessoal e foram morrendo no caminho (...) (VALENTE, 2017, p. 59).
}

Percebe-se, dessa forma, que uma das grandes problemáticas do período era a expulsão de índios de suas terras. Sendo assim, para que se conheça um pouco mais à fundo a problemática, merece atenção o esquema das Certidões Negativas.

A construção dos conceitos de direitos fundamentais na história não é recente. $\mathrm{Na}$ Declaração da Independência dos Estados Unidos, por exemplo, há menção a verdades autoevidentes, como os direitos à vida e à liberdade. O que se observa, por sua vez, é que, apesar de os textos legais trazerem menção expressa ao termo "todos", sempre havia restrições sobre o público alvo desses direitos. As treze colônias, por exemplo, negavam o voto às mulheres, aos negros e aos índios (HUNT, 2009). 
No Brasil, foi negada voz às populações indígenas de várias formas. Uma delas foi o esquema das certidões negativas fraudulentas. O esquema foi descoberto em razão da CPI de 1977 a qual constatou que várias certidões negativas foram concedidas mesmo para áreas habitadas por populações indígenas. Essas certidões tinham o objetivo de permitir a exploração de terras consideradas desocupadas frente aos interesses estatais, mas passaram a ser concedidas também para terras habitadas por índios (BRASIL, 2014a).

Em depoimento, o então presidente da Funai, General Ismarth Araújo de Oliveira, admitiu que a Funai não tinha condições de determinar se havia ou não habitantes nas áreas pleiteadas por investidores:

Em sã consciência, eu não posso afirmar que uma certidão negativa fornecida pela Funai corresponde à realidade. A base de apreciação é o mapa cadastral com a plotação da área fornecida pelo interessado. Se essa plotação foi errada, será dada a Certidão Negativa para uma área e na realidade a sua localização é outra, podendo inclusive, não havendo benfeitorias, se localizar dentro de área indígena (BRASIL, 2014a, p. 256 APUD APUD DCN-S1 17/6/1978, p. 332).

Esse processo foi intensificado em razão de uma resolução da SUDAM, em 1969, que estabelecia que a inexistência de índios nas terras proporcionava incentivos fiscais e financiamentos com vistas à exploração de recursos naturais. A presidência da FUNAI passou, então, a fornecer com ainda menos critérios tais certidões (VALENTE, 2017).

Em verdade, a FUNAI não realizava nenhuma checagem das informações. Dessa forma, se o mapa apresentado contivesse erro ou tivesse sido feito de má-fé, não havia critérios ou fiscalizações que impedissem o fornecimento dessas certidões.

Anos depois, o governo ditatorial se viu obrigado a recuar em relação à emissão de certidões. Isso porque foi montado na própria FUNAI um Plano de Ação Imediata aprovado pelo Ministério do Interior. Uma das orientações era a restrição das emissões de certidões negativas, as quais somente poderiam ser concedidas nas localidades onde houvesse demarcação ou delimitação, conforme Portaria do Ministro do Interior, Mario Andreazza, de 16 de fevereiro de 1981 (VALENTE, 2017).

Para que se tenha ideia da gravidade do ocorrido, somente entre 1970 e 1974, a FUNAI emitiu 772 certidões negativas para empreendedores diversos na Amazônia Legal (VALENTE, 2017).

Esse grande esquema de emissão de certidões negativas, portanto, potencializou a remoção forçada de populações indígenas de terras que eram suas por direito. O resultado foi a separação em massa de famílias, transferências compulsórias, prisões e até massivas contaminações por doenças infectocontagiosas.

Nesse contexto, as remoções forçadas no período ditatorial e a viabilização de uma Justiça de Transição à causa indígena guardam relação desafiadora com a Súmula 650 do STF. Publicada em 31 de outubro de 2003, a Súmula estabelece que os incisos I e XI do art. 20 da Constituição não alcançariam terras de aldeamentos extintos, ainda que ocupadas por indígenas em passado remoto. Significa dizer que as terras que tivessem sido ocupadas por comunidades indígenas que porventura se dispersaram - como ocorreu de maneira forçada na ditadura - não seriam consideradas bens da União, impossibilitando qualquer demarcação.

O precedente responsável por embasar a edição da mencionada Súmula foi o julgamento do Recurso Extraordinário no 219.983-3/SP, de 9 de dezembro de 1998. Nesse julgado, foi estabelecida a impossibilidade de considerar pertencentes à União as terras ocupadas por indígenas em passado remoto, o que contribuiu para o início de uma discussão acerca da fixação de um marco temporal de ocupação. 
Ainda nesse julgamento, o ex-Ministro Carlos Ayres Brito fixou, de acordo com sua interpretação do texto constitucional, que o marco temporal de ocupação deveria ser o da promulgação da própria CRFB, caracterizando-o como sendo um referencial insubstituível no reconhecimento dos direitos sobre as terras tradicionalmente ocupadas (BRASIL, 2009).

A partir daí, outros importantes julgados passaram a aplicar o referido marco temporal a casos concretos, como foi feito durante o julgamento da PET 3388, que tratou do caso Raposa Serra do Sol. Nessa oportunidade, o Plenário do Supremo estabeleceu como marco temporal autorizador a ocupação da terra no dia de 5 de outubro de 1988.

Ainda conforme o mencionado julgado, para a configuração de pertencimento indígena de determinada área, é necessário que sejam preenchidos dois critérios. O primeiro deles é o já mencionado marco temporal de ocupação, que diz respeito à ocupação fática de determinado território em 5 de outubro de 1988 (BRASIL, 2009).

O segundo critério diz respeito ao marco da tradicionalidade, que significa a necessidade de que o grupo ocupante tenha significativa interação com a terra, de maneira que já se tenha construído verdadeira relação entre a comunidade e o solo que se habita. O Supremo destacou que "a tradicionalidade da posse nativa, no entanto, não se perde onde, ao tempo da promulgação da Lei Maior de 1988, a reocupação apenas não ocorreu por efeito de renitente esbulho por parte de não-índios" (BRASIL, 2009, p. 235).

Nesse contexto, é trazido à tona o importante conceito de renitente esbulho. Essa modalidade de esbulho seria a única exceção ao marco temporal explicitado e foi reconhecido na PET 3388, fruto de expressão utilizada pelo ex-Ministro Ayres Britto, que significa a expulsão em virtude de conflito possessório:

O renitente esbulho se caracteriza pelo efetivo conflito possessório iniciado no passado e persistente até o marco demarcatório temporal da data da promulgação da Constituição de 1988, materializado por circunstâncias de fato ou por controvérsia possessória judicializada (BRASIL, 2014b, s.p).

Seguindo essa linha de raciocínio, poderia ser indagado se as remoções forçadas impetradas no período militar estariam abrangidas pelo renitente esbulho e se deveriam ser consideradas como área de ocupação tradicional. A resposta é negativa.

O Supremo já pacificou entendimento segundo o qual renitente esbulho não se confunde com ocupação passada ou desocupação forçada. Para a configuração de renitente esbulho, que autoriza o reconhecimento da ocupação tradicional, é necessário que a disputa pela terra ainda esteja em andamento ou que os indígenas tenham sido expulsos há pouco tempo da localidade.

Já em casos de desocupação forçada em que não tivesse permanecido a disputa territorial até a promulgação da CRFB, o Supremo entendeu não haver direito ao reconhecimento de ocupação tradicional. Esse entendimento foi aplicado no julgamento do ARE 803462 AgR/MS, no qual a última ocupação indígena teria ocorrido em 1953, data da expulsão da comunidade Terena da terra Limão Verde. Nesse caso, o Supremo decidiu que houve desocupação forçada e não renitente esbulho em razão de os índios já não estarem em conflito possessório por aquelas terras em outubro de 1988 (BRASIL, 2014b).

Dessa forma, os povos indígenas vítimas de remoções compulsórias no período de 1965 a 1984, caso desejassem ter sua ocupação tradicional reconhecida, deveriam ter continuado a reivindicar a terra da qual foram expulsos pelo período de 4 a 22 anos, a depender do caso. A solução não parece muito prática, tampouco viável àqueles que se encontravam em situação de vulnerabilidade após terem sido vítimas das arbitrariedades cometidas pelo governo ditatorial. 


\title{
3 OS RELATOS INDÍGENAS SOBRE VIOLAÇÕES DURANTE A DITADURA
}

"Estou cansado de ser um coveiro de índios... Não pretendo contribuir para o enriquecimento de grupos econômicos à custa da extinção de culturas primitivas." Foi o que disse Antônio Cotrim, ex-funcionário da FUNAI, ao se demitir em 1972 (BRASIL, 2014a, p. 229).

Ora, se o regime militar assumia que o percurso a ser percorrido pelos povos indígenas era o de integração a uma dita "civilização", era claro que se esperava que os índios deixassem de ser índios propriamente ditos.

Pelos relatos, observa-se que as expedições realizadas naquele período em muito se assemelhavam às estratégias utilizadas no período colonial:

\begin{abstract}
Criava-se uma frente de atração, que funcionava assim: os sertanistas distribuíam presentes aos índios; esperava-se que estes passassem a retribuir os presentes [...]; na terceira fase, os índios convidavam os sertanistas para conhecer suas malocas; a quarta fase, de consolidação de pacificação, constituía-se no estabelecimento de um acordo pelo qual, em resumo, "civilizados" e índios concordavam em não matar mais uns aos outros. [...] Por último, os índios "pacificados" eram então agregados e entregues aos cuidados de funcionários de um posto, que se encarregava de dar a eles atendimento de saúde e alimentação e ensinar-lhes métodos de agricultura dos "civilizados" (VALENTE, 2017, p. 14-15)
\end{abstract}

O que se sabe, no entanto, é que os povos indígenas resistiram. Os Parakanã, por exemplo, alvo das tentativas de pacificação lideradas pela Funai foram vítimas de cinco transferências compulsórias entre 1971 e 1977, além da morte de 118 indígenas por gripe, poliomielite, malária e blenorragia - doenças trazidas pela própria frente da FUNAI (BRASIL, 2014a):

Eu não sabia que o governo ia fazer estradas aqui. Autoridade não avisou antes de destruir nosso meio ambiente, antes de matar nosso povo. [...] A Funai, que era pra nos proteger, não nos ajudou nem avisou dos perigos. Hoje estamos reclamando. Só agora está acontecendo, em 2013, que vocês vieram aqui pedir pra gente contar a história. Quero dizer: eu não quero mais morrer outra vez (BRASIL, 2014a, p. 234).

Essa foi a fala de Davi Kopenawa, líder Yanomami ao ser entrevistado pela Comissão Nacional da Verdade sobre os massacres ocorridos com o seu povo.

Outras narrativas são igualmente impactantes. Vale a pena conhecer o relato do índio Guarani-Kaiowá Bonifácio R. Duarte, detido em Krenak, uma espécie de reformatório indígena bastante conhecido pelos atentados à dignidade da pessoa humana daqueles que lá estiveram:

Amarravam a gente no tronco, muito apertado. Quando eu caía no sorteio prá ir apanhar, passava uma erva no corpo, prá aguentar mais. Tinha outros que eles amarravam com corda de cabeça prá baixo. A gente acordava e via aquela pessoa morta que não aguentava ficar amarrada daquele jeito. (Prá não receber o castigo...) a gente tinha que fazer o serviço bem rápido. Depois de seis meses lá, chegou o Teodoro, o pai ea mãe dele presos. Agente tinha medo. Os outros apanharam mais pesado que eu. Derrubavam no chão (BRASIL, 2014a, p. 244).

Em entrevista à Comissão Nacional da Verdade, Oredes Krenak confirmou as violações ao dizer que os que estavam em Krenak eram punidos por diversas coisas, inclusive por não querer cumprir ordens de trabalho forçado. Ressaltou, ainda, a proibição de certas manifestações culturais, como o artesanato. Mais um indício que a violência não foi somente física, mas também étnica. 
E os relatos continuam:

\begin{abstract}
Bater era normal para eles. Se o índio tentava se justificar por alguma acusação, batiam com cassetete grande, depois jogavam na prisão. Não podiam nem perguntar por que estavam sendo punidos. Também batiam de chicote. Algemavam o preso dentro da cadeia e ele não podia falar, argumentar. Ameaçavam com arma. Os mais antigos contam que quando matavam um índio, jogavam no rio Doce e diziam pros parentes que tinha ido viajar. Quando estavam muito debilitados, jogavam no hospital. A gente não sabia se estavam mesmo no hospital ou se foram massacrados ou morreram de fome, sede. A gente não via morrer aqui, era quando estavam no hospital. Até a década de 1980 nosso povo sofreu bastante com os militares (BRASIL, 2014a, p. 245).
\end{abstract}

É possível perceber, dessa forma, que os índios foram fortemente atingidos pelas ilegalidades do regime militar, mas de uma maneira bastante peculiar. Foram contaminados, torturados e retirados de seus territórios, tiveram crianças sequestradas, abandonadas e famílias foram desintegradas. A questão é agravada quando se percebe que, além de toda a violência física, houve a perda de elementos culturais em razão da dissipação e extinção de certas etnias, o que torna ainda mais difícil se falar em Justiça de Transição e reparação a esses povos.

\title{
CONSIDERAÇÕES FINAIS
}

Pelo exposto, vale perceber que os relatos juntamente ao trabalho realizado pela Comissão Nacional da Verdade sugerem uma mesma conclusão. O período militar foi marcado por uma intensa violação aos direitos dos povos indígenas, especialmente no que se refere à cultura, às terras e às tradições.

Apesar de os povos indígenas não serem tema central quando se fala em ditadura militar no Brasil e muito embora a problemática apresentada ainda não seja tratada com máxima prioridade em busca de solucionar o real impacto que os povos indígenas sofreram com as políticas de integração da época, a Comissão Nacional da Verdade teve o importante papel de resgatar essas memórias e torná-las públicas.

Vale salientar que, ainda que apenas formalmente, havia legislação capaz de proteger esses povos. Havia, ainda, um procedimento que prezava pela emissão de certidões por órgão oficial para só então permitir que pessoas jurídicas procedessem à exploração de recursos naturais. O problema é que o ordenamento jurídico foi claramente desobedecido.

Sendo assim, o Relatório também teve o papel de trazer à tona questões que precisavam ser investigadas e descobertas. Dito de outra forma, o Relatório da Comissão Nacional da Verdade buscou trazer notoriedade à causa de uma minoria que luta até hoje para ter direitos básicos protegidos e que ainda clama por reparação pelas ilegalidades cometidas, como o retorno aos seus territórios de origem.

Há relatos de morte, tortura, contaminações propositais, além de falhas nas campanhas de vacinação e ausência de profissionais de saúde no contato com os povos indígenas. Nesse aspecto, chama atenção, sobretudo, as políticas e as campanhas de integração, que ignoravam a existência de povos que almejavam apenas a igualdade ao proteger suas tradições. Todavia, a integração era vista como o melhor caminho para o desenvolvimento, pois os índios passaram a ser vistos como verdadeiro obstáculo. Prevalecia uma ideia de superioridade cultural, religiosa e intelectual, a mesma superioridade perceptível nos colonizadores portugueses ao chegarem no Brasil. 
Enquanto se clamava por um rápido avanço econômico, objetivando a construção de estradas para a circulação de mercadorias, os índios que habitavam aqueles territórios tiveram suas pautas esquecidas, ignoradas e foram tratados de forma completamente irregular inclusive pelos próprios órgãos destinados à proteção desses povos, como a Funai.

Por fim, vale ressaltar que, quando se fala em reparação e Justiça de Transição, fala-se em direito à Verdade e à Memória. Apesar de a problemática indígena ter sido trazida à tona pelo desenrolar da busca pelos direitos supramencionados, ainda é difícil falar em reparação para o caso. Isso porque é desafiador quantificar e valorar as consequências. É complexo identificar e punir os agressores.

Ademais, conforme demonstrado, a questão indígena envolve a perda de elementos imateriais, a exemplo dos elementos culturais que foram dissipados como consequência das remoções forçadas e da desintegração de etnias. Ainda assim, vislumbra-se a necessidade de se continuar conhecendo a verdade para buscar as formas mais adequadas de reparação, como o reestabelecimento da ocupação de terras tradicionais indígenas por seus verdadeiros possuidores e a intensificação das garantias indígenas

O que se espera é que períodos como esse jamais se repitam, afinal, foi possível observar que a simples existência de leis não assegura o respeito aos direitos fundamentais de um povo, principalmente quando se trata de uma minoria que ainda luta para deixar vivas suas tradições.

\section{REFERÊNCIAS}

ABREU, Alzira Alves. Serviço de Proteção ao Índio. In: ABREU, Alzira Alves et al. (Org.). Dicionário histórico-biográfico pós-3o. 2. ed. rev. e atual. Rio de Janeiro: Editora FGV, 2001.

ARAÚJO, Ana Valéria. Povos indígenas e a Lei dos "Brancos": o direito à diferença. Ministério da Educação, Secretaria de Educação Continuada, Alfabetização e Diversidade; LACED/Museu Nacional, Brasília, 2006.

BARBOSA, Leonardo Augusto de Andrade. História constitucional brasileira: mudança constitucional, autoritarismo e democracia no Brasil pós-1964. Brasília: Câmara dos Deputados, 2012.

BARRETO, Helder Girão. Direitos Indígenas: Vetores Constitucionais. $1^{\underline{a}}$ ed. 6a impr. Curitiba. Juruá, 2014.

BRASIL. Comissão Nacional da Verdade. Relatório: textos temáticos. Brasília, $2014 a$.

BRASIL. Ministério do Interior. Relatório Figueiredo, 1968. Disponível em: http://www. docvirt.com/docreader.net/DocReader.aspx?bib=museudoindio. Acesso em: 10 jan. 2020.

BRASIL. Supremo Tribunal Federal. Agravo Regimental no Recurso Extraordinário com Agravo 803.462 do Mato Grosso do Sul. Relator Ministro Teori Zavascki. Brasília, DF, o9 de dezembro de 2014b. Disponível em: < http://www.stf.jus.br/arquivo/informativo/documento/informativo771.htm >. Acesso em: 10 abril 2020. 
BRASIL. Supremo Tribunal Federal. Petição 3.388 de Roraima. Relator Ministro Ayres Britto. Brasília, DF, 19 de março de 2009. Disponível em: < http://stf.jus.br/portal/principal/principal.asp >. Acesso em: 10 abril 2020.

CABRAL, Rafael Lamera Giesta; PRADO, Alessandro Martins. Repressão política aos indígenas de Mato Grosso do Sul: uma leitura a partir dos estudos de Justiça de Transição. 2020. No prelo.

CODATO, Adriano Nervo. Uma história política da transição brasileira: da ditadura militar à democracia. Revista de Sociologia Política, Curitiba, v. 25, 2005.

DELGADO, Lucilia de Almeida Naves; FERREIRA, Marieta de Moraes. História do tempo presente e ensino de história. Revista História Hoje, v. 2, n. 4, p. 19-34, 2013.

FREIRE, Carlos Augusto da Rocha. (Org.). Memória do SPI: Textos, Imagens e Documentos sobre o Serviço de. Proteção aos Índios (1910-1967). Rio de Janeiro: Museu do Índio/FUNAI, 2011.

FUNAI, Serviço de Proteção aos Índios - SPI. Brasília, 2013. Disponível em: < http://www. funai.gov.br/index.php/servico-de-protecao-aos-indios-spi >. Acesso em: 07 dez 2019.

HUNT, Lynn. A invenção dos direitos humanos - uma história. Trad. Rosaura Eichenberg. São Paulo: Companhia das Letras, 2009.

LACERDA, Rosane. Os Povos Indígenas e a Constituinte - 1987/1988. CIMI - Conselho Indigenista Missionário, Brasília, 2008.

MAGALHÃES, Juliana Neuenschwander. Diversidade cultural e Justiça de Transição: os casos de perseguição aos índios durante a ditadura militar e a transição política no Brasil. Quaderni Fiorentini per la storia del pensiero giuridico moderno, Firenze, n. 44, tomo II, p. 11371166, 2015.

MARQUES, Raphael Peixoto de Paula. Julgar o passado? Verdade histórica e verdade judicial na ADPF 153. Revista Jurídica da UFERSA, Mossoró, vol. 2, n. 3, 2018. Disponível em: https:// doi.org/10.21708/issn2526-9488.v2.n3.P7o-86.2018. Acesso em: 11 mar. 2020.

PAULETTI, Maucir, et. al. Povo Guarani e Kaiowá: uma história de luta pela terra no Estado de Mato Grosso do Sul. In: CIMI-RMS, Conselho Indigenista Missionário Regional Mato Grosso do Sul, et al. (Org.). Conflito de Direitos sobre as Terras Guarani Kaiowá no Estado de Mato Grosso do Sul. São Paulo: Palas Athea, 2000.

SANTOS, Cecília MacDowell. A justiça ao serviço da memória: mobilização jurídica transnacional, direitos humanos e memória da ditadura. In: SANTOS, Cecília MacDowell (et al.) (Org.). Desarquivando a ditadura - memória e justiça no Brasil. Volume II. São Paulo: Hucitec, 2009. 
SELIGMANN-SILVA, Márcio. Anistia e (in)justiça no Brasil: o dever de justiça e a impunidade. In: SANTOS, Cecília MacDowell (et al.) (Org.). Desarquivando a ditadura - memória e justiça no Brasil. Volume II. São Paulo: Hucitec, 2009.

SILVA, Julianne Holder da Câmara; SILVA, Maria dos Remédios Fontes. Entre Tupã e o Leviatã: o transconstitucionalismo e as ordens locais indígenas. Revista Jurídica da UFERSA, Mossoró, v. 1, n. 1, p. 165-187, 2017. Disponível em: https://doi.org/10.21708/issn2526-9488.v1.n1.p165187.2017. Acesso em: 10 mar 2020.

SOUZA FILHO, Carlos Frederico Marés de. O renascer dos povos Indígenas para o Direito. $1^{\mathrm{a}}$ ed. 8a impr. Curitiba. Juruá, 2012.

TRINIDAD, Carlos Benítez. A questão indígena sob a ditadura militar: do imaginar ao dominar. Anuário Antropológico, Brasília, v. 43, n. 1, p. 257-284, 2018. Disponível em: http://www. dan.unb.br/images/pdf/anuario_antropologico/Separatas_vol_43_n1_julho2018/artigo_a_ questao_indigena.pdf. Acesso em: 10 abr. 2020.

VALENTE, Rubens. Os fuzis e as flechas. História de sangue e resistência indígena na ditadura. Companhia das letras. São Paulo, 2017.

VAN ZYL, Paul. Promovendo a justiça transicional em sociedades pós-conflito. Revista Anistia Política e Justiça de Transição, n. 1 (jan./jun. 2009). Brasília: Ministério da Justiça, 2009. 